\title{
The effect of a machine-rich environment on courseware development: The process and the product
}

\author{
M. NADINE PERKEY \\ Drexel University, Philadelphia, Pennsylvania
}

\begin{abstract}
The development of courseware in conjunction with Drexel's microcomputer program is discussed. Many factors have influenced development, but the machine-rich environment has had the major impact on both the process of development and the type of courseware that has been generated. Integrating the computer as a tool into this saturated environment requires many developers across all curricula. The end result is an enriched development environment that benefits from the exchange of ideas and methods across all disciplines within the University.
\end{abstract}

In 1982-83, Drexel University decided that all students needed an increased knowledge of computer methods and technology in their chosen fields of study. The strategy for achieving this goal was to require student ownership of a microcomputer. Beginning with the 1983-84 academic year, all entering freshmen at Drexel were required to have personal access to a microcomputer. The computer of choice was the Macintosh.

With nearly every student owning a computer, a number of new support units were needed within the university. The Software Development Group (SDG) was formed in direct response to the needs for support to develop courseware material. SDG's primary charge is to assist faculty in the design and implementation of curriculum material for the Macintosh. At Drexel, the formal process of courseware development begins with the interested faculty member's submitting a proposal to the Microcomputer Policy Committee for review. This proposal describes the courseware's content and pedagogical goals, and provides an estimate of the resources required to accomplish the project. Upon approval and subsequent funding of the proposal by the Drexel Microcomputer Program, resources are allocated by SDG.

During the past 2 years, many projects have evolved within each of Drexel's academic colleges. Not surprisingly, the College of Science and the College of Engineering have had the most proposals submitted and funded; however, the College of Humanities and Social Sciences and the College of Design have been unexpectedly active. Not all projects have been successfully completed and

The Microcomputer Project was partially supported for the first three years by funds from the Pew Memorial Trust; this support allowed the Software Development Group to have a direct effect more quickly and more effectively than would otherwise have been possible. Thanks are owed to the colleagues who have participated in the development process, as their experiences and projects have provided the rich data from which this paper was developed. The author's mailing address is: Office of Computing Services, Drexel University, Philadelphia, PA 19104. have produced courseware: some have failed because of technical and implementation difficulties; some because faculty members underestimated the time required. However, the majority of projects have been successful and have not only produced courseware, but have also generated ideas and/or methods which other faculty members have been able to adapt and implement in their own content areas.

\section{THE PROCESS OF COURSEWARE DEVELOPMENT}

When each student has his/her own computer, there is an immediate need for many faculty members to become developers as they begin to incorporate this new resource into the learning environment. With a large number of developers required, it is no longer possible to rely only on faculty members who have an interest or background in computing. Thus, the process of courseware development must provide an avenue that allows a developer to concentrate on the pedagogical goals and the specific content addressed by the application while other resources are provided to design and implement. This approach creates a situation in which many more faculty members can participate than would otherwise be possible.

Although the faculty member has considerable freedom in organizing his/her project, the dominant model has been to form a team consisting of the faculty member, an SDG professional, and usually at least one student programmer. The team may also incorporate other interested faculty members, graduate students, or part-time undergraduate students. The faculty member is the content specialist who prescribes the pedagogical objectives and serves as the major architect for the flow of the material to be presented (Hewett, 1986). The SDG professional consults and advises on program design and user-interface issues, furnishes a bridge to material which already exists as well as materials under development, and provides programming/technical expertise that includes oversee- 
ing the flow of the program, specifying data structures, and identifying and programming difficult algorithms.

Generally the student programmer (a full-time cooperative education student) is the major implementor or builder of the program as designed by the faculty member and SDG professional. Incorporation of student programmers into the team has proven to be very beneficial to the design process because (1) students frequently have more time and energy to devote to a project than anyone else on the design team, (2) students are not limited by traditional boundaries and "what can't be done" and, thus, sometimes produce very creative solutions, and (3) the students can represent the viewpoint of the ultimate user of the courseware in a way none of the other team members can. In addition, a wonderful synergy can occur between the faculty member and the student if the faculty member encourages and fosters the student's participation regarding the content and presentation of the material. This interaction can free the creative talents of the student and allow the student to become truly involved as part of the team.

At the faculty member's discretion, each team is configured with major management responsibility residing either with the faculty developer or with the SDG professional. Currently, almost all of the projects which require a full-time student programmer (better than half of SDG's projects) are directly managed by SDG professionals. Other models for development are being utilized by faculty members, but for every funded proposal, there is an assigned SDG professional contact to whom faculty members can turn for consultation and technical expertise.

Since each involved faculty member is not required to be an expert in design or implementation, there is a need for a centralized facility to house technical knowledge and to provide a communication link. Thus, SDG not only provides resources but also serves as the focal point for development. This includes serving as a communication link among projects, training programming staff, educating/informing faculty of available tools and techniques, archiving existing material, and developing and maintaining a software data base of specialized modules which allows these modules to be used by other project teams. The skills necessary to design and implement courseware material have a common foundation which favors a centralized support group that individual faculty members can directly use and quickly transform to their specific courseware.

The SDG also provides support to the entire university community by testing new development tools, by building specialized utilities needed for development, and by testing new or prerelease products (software and hardware) that the university may purchase.

\section{THE PRODUCTS OF COURSEWARE DEVELOPMENT}

The nature of material produced at Drexel has ranged in type from practice and exploration material to microworld simulators, in sources from real to imaginary, and in goals for courseware from replacing things that work to posing problems for analysis and solution (Hewett, 1986). Most Drexel-produced courseware can easily be classified as to its general type and source; however, a well-rounded tool will almost always have two or three goals associated with it. Each of these types, sources, and goals has a place in a university curriculum, but in an environment in which each student has his/her own machine, there is an increased emphasis on development of courseware tools that provide the student with the ability to explore and manipulate the underlying knowledge base.

With a machine-rich environment and the emphasis on the computer as a tool, courseware tools have been adapted from materials for a specific content to a more general format for which the content can easily be specified by the faculty member without requiring additional programming or a long development process. Additionally, a computer-saturated campus creates a large demand for tools that are not specific to a given content area. Naturally, where cost factors permit, commercial packages are purchased and provided, but some tools (such as a plotting package and a telecommunications package) have been developed in-house and provided at no cost to Drexel students.

\section{Practice and Exploration Material}

Practice and exploration material not only incorporates the traditional learning environment of improving basic skills through repetition, but also includes exploration and manipulation of a knowledge base in some way. Whereas some early programs of this type developed at Drexel resemble traditional drill and practice, the emphasis has shifted toward exploration of a block of knowledge. This shift has been directly fueled by the programs that allow manipulation of the underlying knowledge constructs.

Although the practice and exploration material developed at Drexel also provides immediate feedback to the student's response as well as a large or variable set of problems, in a machine-rich distributed computing environment, there are operational contingencies that preclude electronic tracking of a student's mastery of the material as is generally considered desirable for drill and practice material. When students are in control of the medium upon which the material is stored and the medium is easy to duplicate, modify, and transmit, there is no way to ensure the integrity of the data gathered. Removing this traditional requirement also contributed to the shift from drill and practice to practice and exploration.

Vocab. An example of a practice and exploration application is the Vocab program, ${ }^{1}$ designed because some students were unable to learn historical information from a textbook. They did not have the necessary vocabulary. Vocab drills the students on three word categories: nouns, verbs, and modifiers. Each quiz is associated with a particular chapter in the required textbook. Once a word category is selected, the user is presented with 10 words 
la

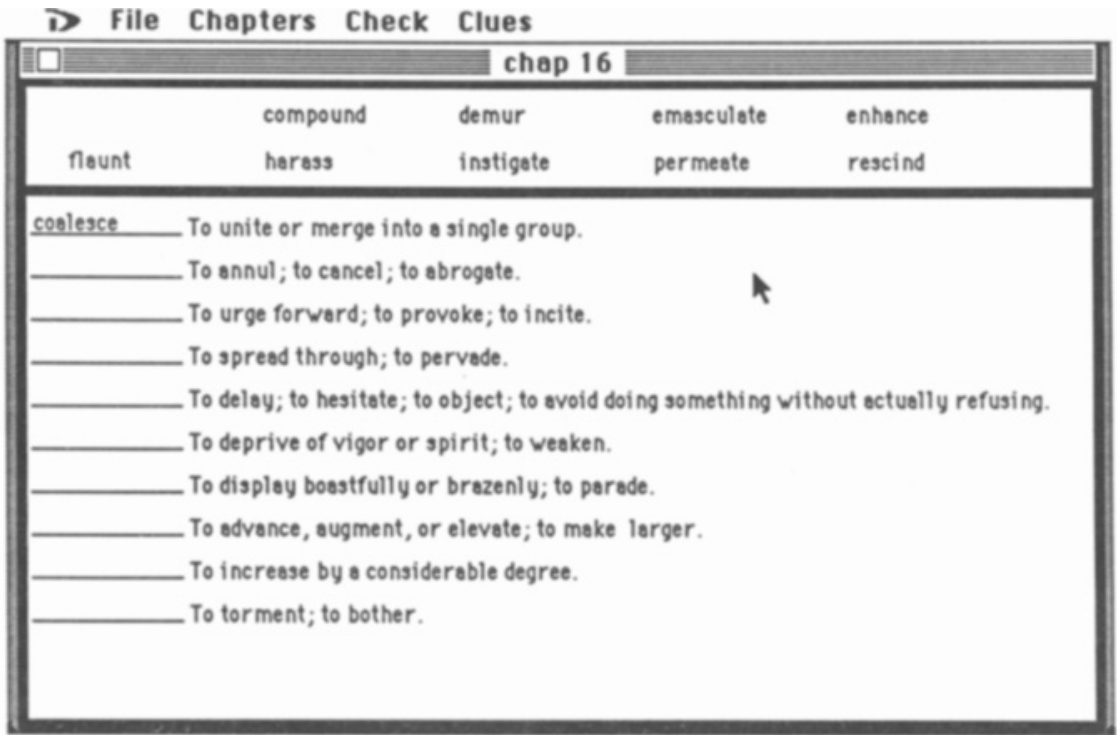

D File Chapters Check Clues

$1 b$

\begin{tabular}{|c|}
\hline Clues \\
\hline $\begin{array}{l}\text { "Because these meetings [of Estates general and parliaments] provided opportunities for } \\
\text { opposition to the crown to coalesce, absolute monarchs eventually stopped summoning them." }\end{array}$ \\
\hline $\begin{array}{l}\text { "[English] fear [of Cotholicism] was compounded by o cruciel fact: although Charles had } \\
\text { produced several besterds, he had no legitimate children." }\end{array}$ \\
\hline "Whoever was old enough to serve [Louis XIV] did not dere demur. \\
\hline $\begin{array}{l}\text { "Louis XIV...through painstaking attention to detail and precisely calculated showmanship } \\
\text {... emasculated the major threat to his absolute power." }\end{array}$ \\
\hline "Nature itself was subdued at Versailles to enhance the greatness of the king." \\
\hline $\begin{array}{l}\text { "The extravegance and licentiousness of James' court, and the public flaunting of his male } \\
\text { lovers, weokened respect for the monerchy." }\end{array}$ \\
\hline $\begin{array}{l}\text { "Henry[IV of France] denied influence on the royal council to the nobility, which } \\
\text { had harassed the country for half o century." }\end{array}$ \\
\hline "Cherles thus instigated militery action against parliamentery forces." \\
\hline "Pessimism and fatalism permeated [Spanish] notional life." \\
\hline $\begin{array}{l}\text { "Understanding and peace were not achieved, however, partly because radical members of the } \\
\text { Commons pushed increasingly revolutionary propositions, partly because Charles } \\
\text { maneuvered to rescind those he had al ready approved." }\end{array}$ \\
\hline
\end{tabular}

Figure 1. Illustrative frames from Vocab.

and 10 definitions which have to be matched (see Figure 1). While taking the quiz, the student may track his/her performance and obtain clues for the words. The clues are direct quotes from the textbook; thus, the clue places the vocabulary word in content-area context. Vocab provides both an immediate feedback to the student's response and a large set of words from the textbook.

The Vocab format has been adapted and extended for presentation of material in a photography laboratory (Photography Worksheet). ${ }^{2}$ The vocabulary words as well as the definitions now contain mixed alphanumeric strings. This capability further extends the basic concept into other disciplines (Figure 2). In addition, a checking function was added. This function permits a quick visual check of which matches are incorrect. Finally, the clues function has been extended to show either clues for all definitions, clues for wrong answers only, or clues for unanswered questions.

This adaptation triggered the generalization of Vocab into a generic product, called MatchMaker, which has the same features and format as Vocab but which can be used in any discipline to generate vocabulary quizzes. Essentially, a faculty member is provided with a blank MatchMaker and uses a tool to load his/her quiz(zes) into MatchMaker without requiring a recompilation of the original program.

PeriChart. An extension of a practice and exploration application to include dynamic access to the knowledge base associated with the periodic chart (Figure 3a) is 



Figure 2. Illustrative frames from Photography Worksheets.

provided by a program called PeriChart. ${ }^{3}$ PeriChart has aspects of traditional drill and practice, which are exemplified by Figures $3 b-3 d$. However, other aspects of the program include the ability to select groups of elements, to call up comparison data, and to plot the comparison data (Figures $3 \mathrm{e}-3 \mathrm{~g}$ ). Thus, the package can provide a visual representation of a chosen characteristic of associated elements forming a bridge to the underlying relationships that are the foundation of the periodic chart. Additionally, PeriChart contains another feature which is not easily replicated by standard reference material: it can calculate the molecular weight of an entered chemical formula.

Matrix Algebra. Another application that demonstrates the tool aspects of practice and exploration is Matrix Al- gebra, ${ }^{4}$ which presents the user with a predefined matrix that can be used for instruction in a step-by-step reduction mode or can be used as a tool to find the desired solution. The user can input a problem in either matrix form or equation form (Figure 4). A variety of operations are permitted, including swapping rows, multiplying by a constant, reducing rows automatically, inverting a matrix, and multiplying a matrix. In addition to the step-by-step function, the user can revert to a prior matrix at any point in the operation and also can revert to a prior system at any point in the operation. This application provides aspects of practice by providing the feature of stepping through the matrix operation with its attendant explanation, but it is also a tool which allows exploration of a 
$3 \mathbf{a}$

* File Data Comparison Tables Analysis

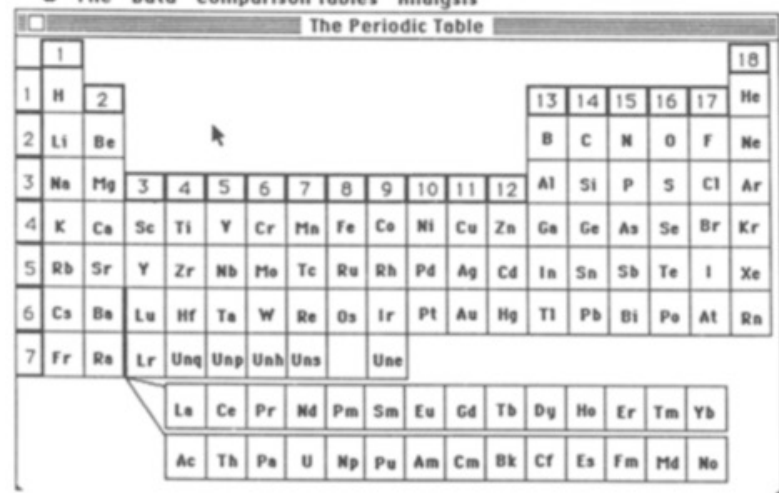

$3 c$

* File subjects

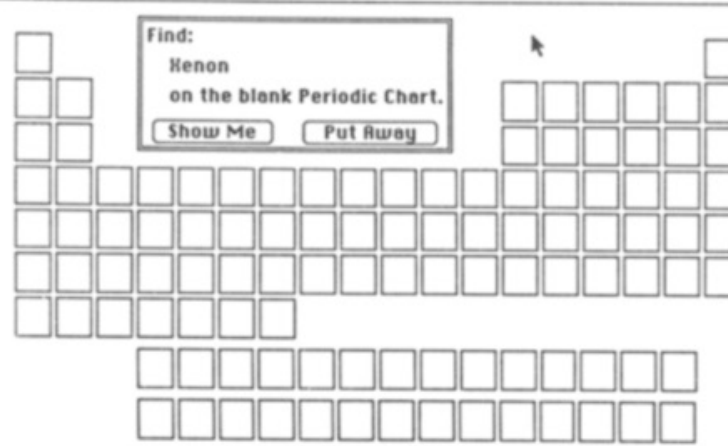

$3 e$

* File Data Comparison Tables Analysis



3b

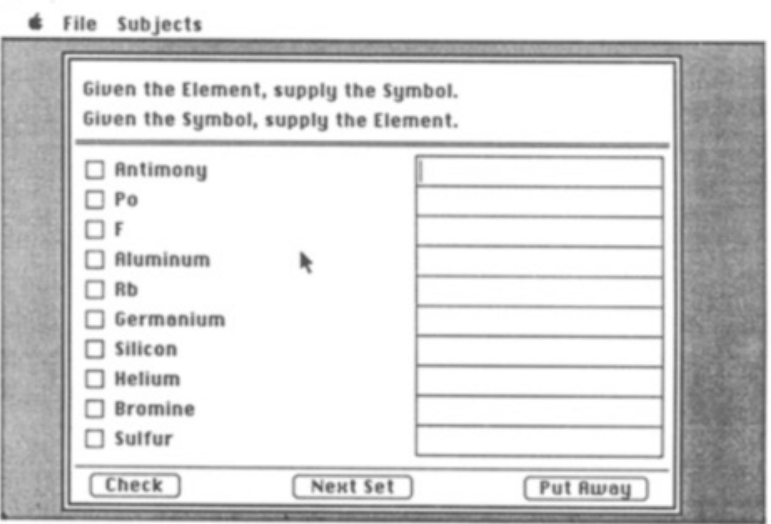

3d

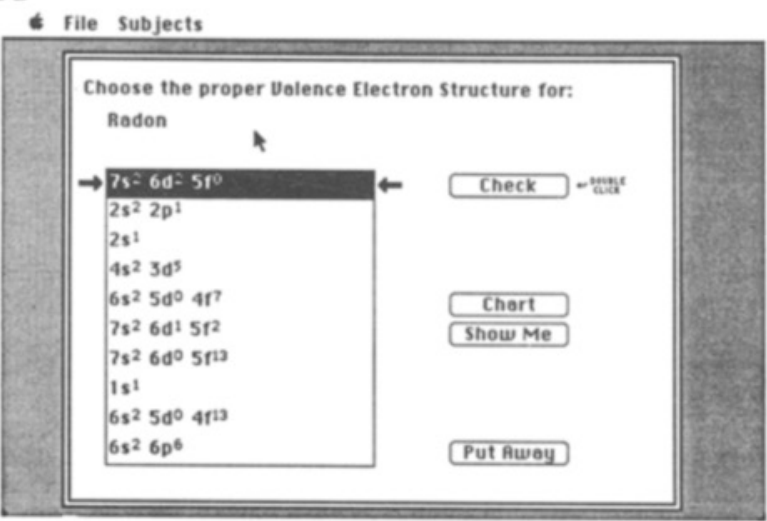

$3 f$

* File Data Comparison Tables Analysis

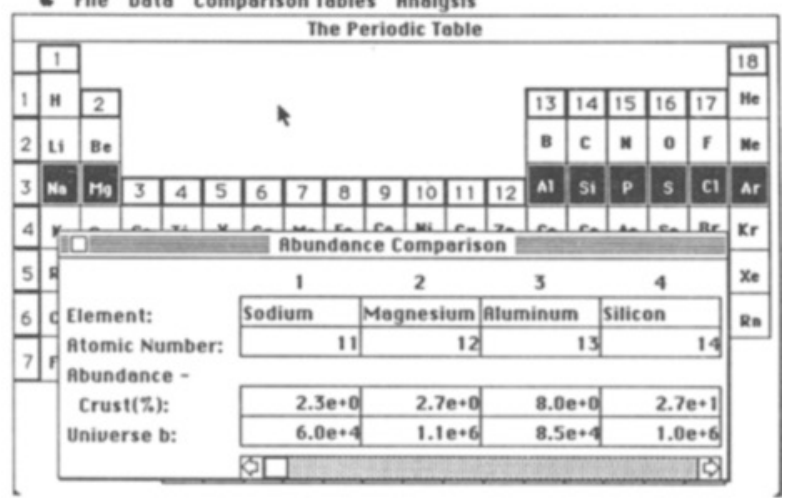

* File Data Comparison Tables Analysis

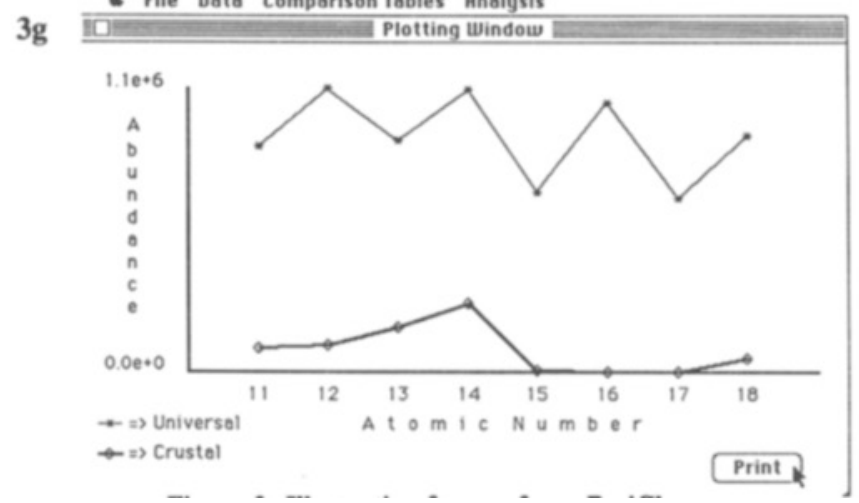

Figure 3. Ilustrative frames from PeriChart. 


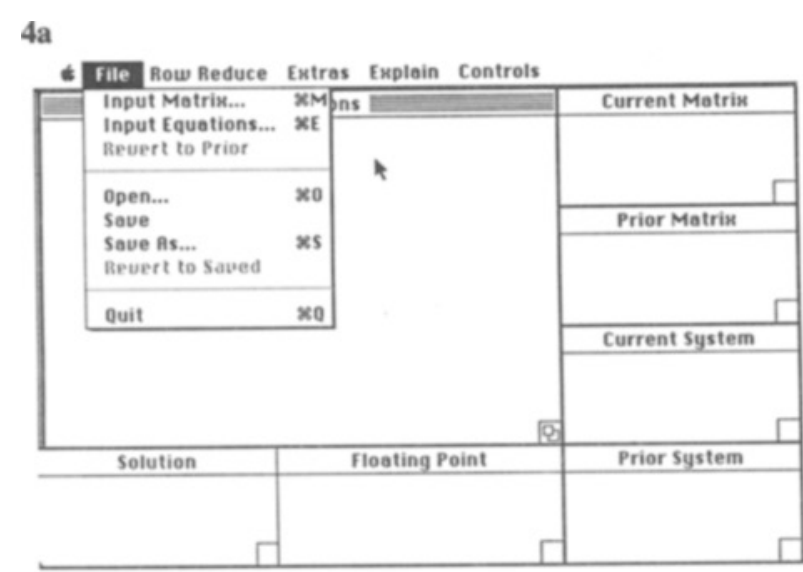

$4 \mathrm{~b}$

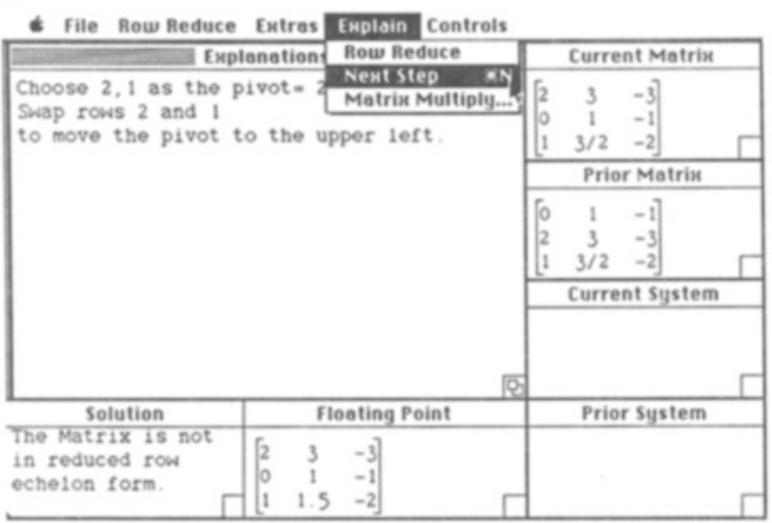

$4 c$

\begin{tabular}{|c|c|c|c|}
\hline \multicolumn{3}{|c|}{ Explanations } & Current Matrix \\
\hline Continue Stop & \multicolumn{2}{|r|}{ 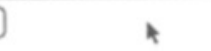 } & \multirow{2}{*}[\begin{array}{cccc}{1/2}&{2}&{9/2}&{2}\\
{0}&{4}&{8}&{2}\\
{1}&{0}&{17}&{6}\end{array}]{} \\
\hline \multirow{3}{*}{\multicolumn{3}{|c|}{$\begin{array}{l}\text { Choose a pivot. } \\
\text { Look at column } 1 \text { starting with row } 1 . \\
\text { We find the first non-zero entry in } \\
\text { the column is in row } 1 \text {. } \\
\text { Thus, our pivot value is } 1 / 2 \text {. } \\
\text { Since the first entry checked in the } \\
\text { column was non-zero, no row swapping } \\
\text { is needed. }\end{array}$}} & \\
\hline & & & Prier Matrix \\
\hline & & & {$\left[\begin{array}{cccc}1 / 2 & 2 & 9 / 2 & 2 \\
0 & 4 & 8 & 2 \\
1 & 8 & 17 & 6\end{array}\right]$} \\
\hline & no $\mathrm{rod}$ & ow swapping & \begin{tabular}{|r|} 
Current system \\
$1 / 2 \mathrm{X}_{1}+2 \mathrm{X}_{2}+9 / 2 \mathrm{X}_{3}=2$ \\
$4 \mathrm{X}_{2} * \quad \Delta \mathrm{X}_{3}=2$ \\
$\mathrm{X}_{1}+8 \mathrm{X}_{2} \cdot 17 \mathrm{X}_{3}=6$
\end{tabular} \\
\hline Solution & & flooting Point & Prior 5 \\
\hline $\begin{array}{l}\text { The Matrix is not } \\
\text { in reduced row } \\
\text { ochelon form. }\end{array}$ & {$\left[\begin{array}{cc}0.5 & 2 \\
0 & 4 \\
1 & 8\end{array}\right]$} & $\left.\begin{array}{ccc}2 & 4.5 & 2 \\
4 & 0 & 2 \\
0 & 17 & 6\end{array}\right]$ & $\begin{array}{r}1 / 2 X_{1}+2 X_{2}+9 / 2 X_{3}=2 \\
4 X_{2} * 8 X_{3}=2 \\
X_{1}+8 X_{2}+17 X_{3}=6\end{array}$ \\
\hline
\end{tabular}

Figure 4. Illustrative frames from Matrix Algebra.

variety of problem sets of the user's choosing to solve a set of equations and satisfies the goal of posing problems for analysis and solution.

\section{Data Generators}

Data generators are applications that contain a data model of some kind and permit the user to design an experiment within certain given constraints. The applica- tions then use the constraints of the model to generate data (an answer set), which the user analyzes.

Signals. The generation of waveforms, the creation of combined waveforms, and the execution of Fourier analysis is the primary emphasis of Signals. ${ }^{5}$ This application provides exploration of seven different waveforms: impulse, step, ramp, exponential, sine, pulse, and point by point. These waveforms are prespecified by the program, but the user is allowed to change certain parameters associated with the waveforms to generate his/her own signals (experiment). Signals provides a variety of operations that can be performed upon a waveform, including time shift, adjustment of amplitude or time scale, inverting, flipping, and so forth (Figure 5). Additionally, the user can select two waveforms and perform the following set of operations: addition, subtraction, multiplication, division, convolution, and correlation. A variety of waveforms can be stored and manipulated at one time, plus the application has been extended to allow Fourier analysis of a selected waveform. This tool can be used in either a real or an imaginary mode and serves at least two goals: (1) providing data to be observed and described and (2) allowing problems to be posed for analysis and solution. An additional bonus of this application is that it allows the student to explore more advanced, complicated problems than would normally be possible; thus, the problem sets are more realistic and can more closely represent problems encountered in the field.

\section{Experiment Simulators}

Experiment simulators are applications that enable the student to run an experiment or become part of the experiment. This interactive learning situation not only allows students to explore certain parameters of the experiment but allows them to extend the computer to serve as a data collection device or as a piece of experimental apparatus, which helps break down the idea that computers are strictly for working with numbers.

Perceptual and Motor Skills. The application Perceptual and Motor Skills ${ }^{6}$ simulates a traditional looking mirror-tracing task. This program allows the response to movement to be reversed either left to right or up to down, or both directions can be reversed at the same time. Additionally, the computer is used as a data collection device to automatically record both the required time to complete the task as well as time on target versus time off target, thus freeing the user to explore the underlying concepts of the experiment instead of being bogged down with the details of data collection (i.e., the traditional stopwatch, etc.). One clear goal for this tool is to replace something that already works (i.e., a traditional mirrortracing setup in a laboratory), but it also simulates a specialized situation by timing reaction and providing feedback on reaction time. Additionally, the traditional experiment can be extended by the tool's new capability of reversing both directions at once. (For additional details about this application, see Chute, 1986.)

ProblemSolver. Another example that allows the student to use the computer as part of an experiment is 
5 a

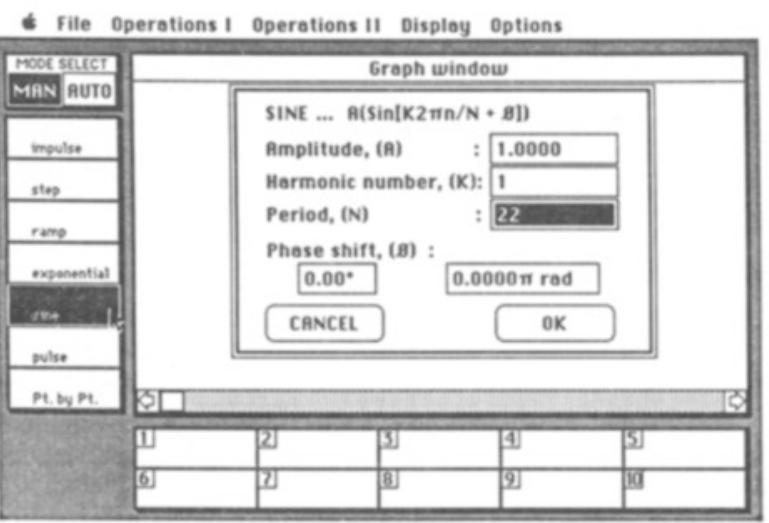

$5 b$



$5 c$

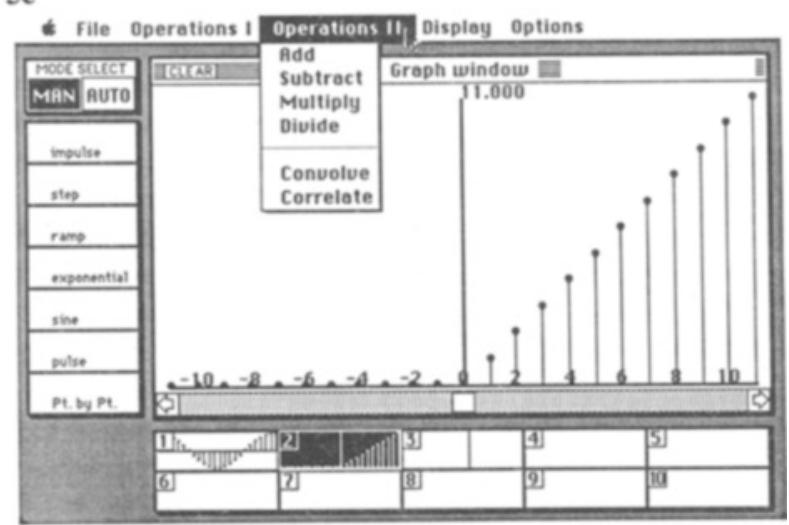

Figure 5. Illustrative frames from Signals.

demonstrated by ProblemSolver. ${ }^{6}$ The basic idea is for the student to guess a five-letter word (familiar or unfamiliar stimulus) that has been randomly selected from a data base. This package allows the student to set feedback parameters, set time limits for guesses, and record completion time. After collecting the data, the student is asked to evaluate the effectiveness of individual versus group problem solving by making comparisons between time to complete under four different conditions: in- dividual coupled with a familiar stimulus, group coupled with a familiar stimulus, individual coupled with an unfamiliar stimulus, and group coupled with an unfamiliar stimulus. This experiment satisfies the goal of providing behaviors to be observed and described (parenthetically, the application plays an active role in the observed behavior) as well as creating a special-purpose tool that collects some of the relevant data for the experiment. (For additional details about this application, see Chute, 1986.)

\section{Microworld Simulators}

Applications in this category create a microworld, which represents either a real or an imaginary world with a set of rules governing behavior in that world.

BRS/Search. One example of a simulation of a real microworld is the BRS/Search. ${ }^{7}$ The rules in this microworld adhere to the syntax needed to search an online data base, marketed by a commercial vendor, BRS ${ }^{\mathrm{TM}}$. The underlying concept of this package is to expose the student to the process of searching without the associated on-line costs of actually linking to BRS. To accomplish this, a subset of the real data base has been downloaded. Then, upon command, the simulator searches this subset and provides the appropriate response. Obviously, the user is required to use the same syntax as would be needed on-line; however, the user can request the simulator to interpret the search entry, thus providing feedback to the user that the commercial data base does not. Once the user is comfortable with the searching syntax, he/she is then ready to progress to an on-line search in preparation for his/her research paper. Obviously, one goal of this application is to simulate the special environment of the BRS, but it also creates an enhanced situation in which the user's response is interrupted by the application.

Karel. An example of a simulation of an imaginary microworld is Karel. ${ }^{8}$ Karel, a Macintosh implementation of a language designed by Pattis (1981), allows exploration of certain conventional programming syntaxes in a graphic way (Figure 6). The user can be presented with an environment, Karel's World, and then asked to create a set of rules (or program) that responds directly to this environment. For instance, in one environment, Karel the Robot is in a room with only one door, and the user must create the rules that will allow Karel to exit the room, without regard of either Karel's starting place or direction. The application allows the user to input the rules as well as to watch the rules being executed, step by step in the listing and graphically in the graphics window. Karel not only simulates a programming environment, but the graphic capabilities provide an opportunity to observe programming in a concrete way, and the application allows problems to be posed for analysis and solution.

\section{Tools Not Related to a Specific Content Area}

Special-purpose tools are also being developed. Tools in this category are designed to provide a function, such as plotting. These applications frequently make extended 


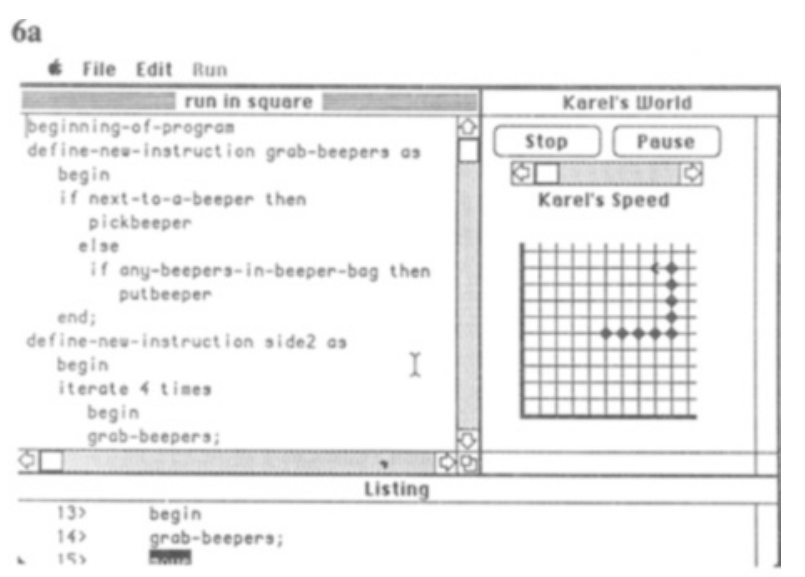

$6 \mathrm{~b}$

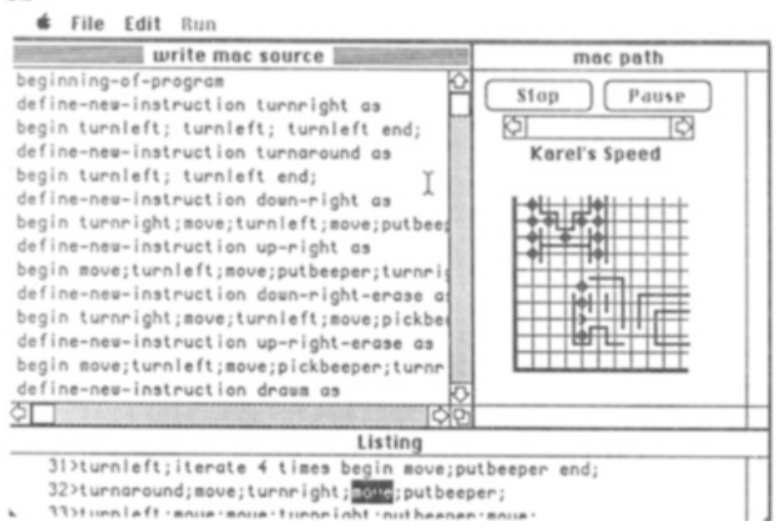

Figure 6. Illustrative frames from Karel.

use of the computing power of a machine. They are not tutorial or remedial in nature, and they expect the user to have the necessary terminology and background to use the tool effectively. Tools frequently enable the teacher to extend the problem sets to more difficult and timeconsuming problems than one would normally expect a student to accomplish without the tool. However, incorporation of these tools into a curriculum may require a major reworking of the problem sets by the teacher and, thus, add a burden on the teacher to carefully integrate this additional material into the course.

\section{THE SPIN-OFF EFFECTS}

Spin-offs are possible because (1) there is a central support unit (i.e., the Software Development Group); (2) there is ready access to machines and, consequently, there are developers who can benefit from the work of others; and (3) there are a variety of specialized tools which have been developed that allow faculty to use generic formats.

\section{Adaptation}

Adaptation is a source of ideas for development which is frequently overlooked. Adaptation takes a traditional or discipline-specific tool and extends its applicability or function into another area or takes an existing application and applies its basic concepts to another discipline. Some examples of the former are the use of the electronic spreadsheet in such diverse areas as creating a nutritional data base, teaching introductory physics for nonmajors, and modeling the neural circuits in the eye (Hewett, 1985). Examples of the latter are the adaptation of the basic flow/user interface of an application by another discipline, such as that described earlier, Vocab to Photography Worksheet. Another example of adaptation involves a product that displays a map of pre-World War II Europe and asks the student to use the mouse to select regions on the map representing various geographic areas that played a pivotal role in the Treaty of Versailles. The basic flow of this work and its underlying user-interface concepts have been adapted to display the human brain, eliciting responses from the user based on the function of the different areas of the brain.

\section{Development from Specific to General Formats}

It was the adaptation of an application to another discipline that resulted in the birth of a generic application, MatchMaker, which has the same format as Vocab or Photography Worksheet, but allows a faculty member to prepare a tailored quiz using the general format. The end result is a stand-alone quiz, whose contents have been specified by the faculty member without requiring a recompilation of the original application.

In some cases, the intent from the onset of the design process has been to develop a generic application. A program called CaseMaker was first proposed for a business law course. However, it had the necessary components to be applicable to other areas, such as sociology or psychology; thus, the program was designed from the beginning to have a general format whose contents could be specified by a particular faculty member. CaseMaker presents the facts or case study of a particular situation, and then presents the student with questions regarding the case study. After the student specifies one of two branches, the student is required to select a rationale for choosing that branch from a list of possible rationales. Each rationale has an accompanying explanation either indicating its correctness or the reason it was incorrect. The student is then presented with the branching choice again (after three branches, he/she can either request the correct answer or keep on trying).

\section{Evolution of Lecture/Demo Material to Practice and Exploration}

A number of short modules were originally designed for use during a lecture period in physics and mathematics covering concepts which have traditionally proven difficult for students to understand. This lecture/demo material is used to provide graphic or dynamic illustration of the concept. Examples include animated vector addition, classic collision and projectile problems, or the presentation of a graphic solution on a coordinate plane of an equation. Some of this material has been extended to include limited 
"what if" exploration of the concepts being presented and consequently has resulted in the development of "minimodules" for students' use outside the lecture hall.

\section{CONCLUSION}

Courseware development at Drexel has first and foremost been shaped by those people who are actively involved. The environmental factors that have been important include the machine-rich environment, the emphasis on the computer as a tool, the underlying support structure provided, the models chosen for faculty/professional interaction, and the feedback from the process of development itself. Of these, the machine-rich environment is the dominant factor, as it has directly or indirectly affected all the other environmental factors mentioned. When every student has a machine, there is an implied pressure to utilize the machine to justify its purchase. This perceived pressure has resulted in curricula being evaluated and modified. Consequently, several teachers have examined their pedagogical objectives, with some being drawn into the courseware development process. Many of these faculty members were not computer experts.

When complete freedom of access to a machine is coupled with the desire to diffuse the technology across all disciplines without requiring all students to become programmers, the role of the computer as a tool emerges. Although Drexel provided each student with a word processing package, a graphics package, a spreadsheet package, a database package, and two languages as general-purpose tools which are applicable across all disciplines, there is still a need for tools that fit the needs and requirements of specific disciplines. Furthermore, with each student using his/her own computer and the courseware in his/her own work-study place, the courseware must be able to stand alone. These factors have influenced faculty developers to create applications which are more dynamic and interactive and which extend standard courseware material by providing access to a richer knowledge base. The diffusion of the computer across all disciplines has encouraged the extension of developed material. As this body of material has grown, the adaptation of a concept to other disciplines has resulted in the extension of specific themes to general themes and has eventually affected the development process itself by giving rise to the concept of generic formats being considered in the design process itself.
It is interesting to note that many of the adaptations from one use to another have occurred in the humanities area. In some ways, it appears as though faculty members who are not constrained by preconceived models of what can be done with a computer are freer in their development approaches. This is due partially to the Macintosh's desktop metaphor user interface. It is easy to use, and the consistency it offers frees both the user and the developer from worrying about details that are required in a more traditional computing environment. Similarly, the Macintosh's graphic capabilities open up new vistas for development.

Almost every piece of courseware material developed has had a synergistic ripple effect, first affecting those directly involved in the course, then affecting other courses within the department, then affecting courses outside the department and possibly other development projects. As the body of existing work has expanded, it has resulted in a plethora of ideas from which to draw and, thus, has fueled new development.

\section{REFERENCES}

Chute, D. L. (1986). MacLaboratory for psychology: General experimental psychology with Apple's Macintosh. Behavior Research Methods, Instruments, and Computers, 18, 205-209.

HewetT, T. T. (1985). Teaching students to model neural circuits and neural networks using an electronic spreadsheet simulator. Behavior Research Methods, Instruments, and Computers, 17, 339-344.

HeweTt, T. T. (1986). When every student has a computer: A new perspective on courseware and its development. Behavior Research Methods, Instruments, and Computers, 18, 188-195.

PatTis, R. E. (1981). Karel the Robot: A general introduction to the art of programming. New York: Wiley.

\section{NOTES}

1. Vocab was developed by Stanley Wasson, History-Politics Department.

2. Photography Worksheet was developed by David Staebler, College of Design.

3. PeriChart was developed by James Friend, Chemistry Department.

4. Matrix Algebra was developed by Bernard Kolman, Department of Mathematics and Computer Science.

5. Signals was developed by Banu Onaral, Department of Electrical and Computer Engineering.

6. Perceptual and Motor Skills and ProblemSolver were developed by Douglas Chute, Department of Psychology and Sociology.

7. The simulation BRS/Search was developed for Harold Kollmeier, Department of Humanities and Communications.

8. Karel was developed by Todd Rimmer, Department of Mathematics and Computer Science. 